\title{
Reflections about the optimisation of the treatment of tendinopathies with PRP
}

\author{
Jean-François Kaux ${ }^{1,2,3}$ \\ Marc Bouvard 4 \\ Christelle Lecut ${ }^{5}$ \\ Cécile Oury 6 \\ André Gothot 5 \\ Mikel Sanchez ${ }^{7}$ \\ Jean-Michel Crielaard1, 2, 3
}

1 Department of Physical Medicine and Sports Traumatology, CHU Liège, Belgium

2 Department of Pluridisciplinary Medicine and Sports Traumatology (SPORTS ${ }^{2}$ ), CHU Liège, Belgium

${ }^{3}$ Department of Motricity Sciences, University of Liège, Allée des Sports, Belgium

${ }^{4}$ Centre for Biology and Sports Medicine, Pau, France

${ }^{5}$ Laboratory Hematology Department, University of Liège, University Hospital Sart-Tilman, Liège, Belgium

6 Laboratory of Thrombosis and Haemostasis, GIGA - Cardiovascular Sciences, University of Liège, Belgium

7 Unidad de Cirugía Artroscópica, Vitoria-Gasteiz, Spain

Corresponding author:

Jean-François Kaux

Department of Physical Medicine and Sports Traumatology, $\mathrm{CHU}$ and University of Liège

Avenue de l'Hôpital, B35

4000 Liège, Belgium

E-mail: jfkaux@chu.ulg.ac.be

\section{Summary}

Background: platelet-rich plasma (PRP) infiltration represents a recent therapy for chronic tendinopathies. However, in the literature, this treatment remains controversial.

Purpose: we suggest some ideas for improving this treatment.

Methods: these suggestions were based on a review of published studies and our clinical experience.

Conclusion: optimizing the technique for PRP collection is paramount. Different risk factors must be corrected before infiltration and chronic tendinopathies must be carefully selected. Finally, post-infiltration rehabilitation remains absolutely critical. Standardization of the use of PRP remains necessary in order to optimize the results.

KEY WORDS: platelet-rich plasma, $P R P$, rehabilitation, optimization.

\section{Introduction}

Platelet-rich plasma (PRP) infiltration represents a recent therapy for chronic tendinopathies. Indeed, during degranulation, platelets release cytokines and growth factors (VEGF, PDGF, TGF- $\beta$, IGF-I, and HGF) that promote angiogenesis, tissue remodeling (bone, skin, muscle, tendon, etc.), and wound healing ${ }^{1}$. Most of the preclinical studies showed that PRP stimulates tendon healing process ${ }^{2}$. Thus, PRP could be an attractive therapeutic option for treating chronic musculoskeletal conditions, such as tendinopathy ${ }^{3}$. However, this treatment remains controversial ${ }^{4}$. Major difficulties in comparing and pooling clinical results stem from the fact that PRP is applied in different tendons (lateral epicondylitis, supraspinatus, patellar, Achilles...) and that outcome measurements vary between studies, even in those performed in the same tendon: e.g. epicondylitis, which is the most studied tendon, the variety of clinical scales makes comparisons difficult 4,5 . Based on the literature and our experience, we suggest some avenues for optimizing this treatment 6

\section{Preparing PRP}

Result variability may be explained by a misknowledge about PRPs ${ }^{7}$. Depending on how they are obtained and prepared, PRPs (or Platelet-Released Growth Factors PRGF) present highly variable concentrations of platelets ${ }^{8-10}$, erythrocytes and leukocytes. It is still necessary to optimize the techniques for obtaining and concentrating PRPs and standardizing the injection. Ideally, platelet concentration should be three to four times that of whole blood, i.e. between 600,000 and 900,000 platelets per microlitre $11-14$; a concentration higher than 1,200,000 platelets may, indeed, be unfavorable ${ }^{14}$. Ideally, a reproducible PRP (with identical platelet concentration) should be injected to all patients. Currently, only platelet collection using an apheresis machine enables these objectives to be easily achieved ${ }^{15,16}$. The presence of white or red blood cells could be ad- 
verse to tissue healing process. It was demonstrated in vitro and animal studies that their absence limits the inflammatory response ${ }^{17}$. However, clinical positive effects of pure-PRP have not been demonstrated in controlled studies yet, and, in many clinical controlled studies, only a slight reduction of pain was obtained after a leukocyte rich-PRP injection. Moreover, it has been demonstrated that the anti-bacterial effect of PRP against Staphylococcus aureus, Staphylococcus epidermidis, Propionibacterium acnes and meticillin-resistant Staphylococcus aureus was not linked to the presence of leukocytes ${ }^{18}$.

Finally, platelet activation is reduced postprandially ${ }^{19}$. Moreover, a gentle mastication is able to induce the release of pro-inflammatory components into the bloodstream, especially when patients have severe periodontal disease 20 .

Thus, it would be preferable that patient should be fasting before preparing the PRP to reduce pro-inflammatory factors in platelet concentrate.

In addition, aspirin, corticosteroids and NSAIDs affect platelet functions and should be avoided at least during 10 days before blood collection ${ }^{21-23}$.

Centrifugation speed should be set to a maximum of $900 \mathrm{rpm}(100 \mathrm{~g})$, since a higher speed can lead to platelet activation and resulting decrease of platelet reactivity ${ }^{21,24}$.

After blood collection, it is mandatory to prepare the PRP as soon as possible (ideally within 1 hour) to avoid undesired non-specific platelet activation $21,23,24$. The PRP is stable for about 3 to 4 hours at room temperature, but platelets can become refractory to agonist stimulation 21,23,24. Usually, citrate (or ACD-A) anticoagulation is highly recommended because it better preserves blood and ex vivo platelet reactivity. In contrast, EDTA and heparin should be avoided due to decreased platelet reactivity leading to reduced release of growth factors ${ }^{21,23-26}$.

\section{Correcting tendinopathy risk factors}

Before planning any PRP infiltration, it is essential to undertake a precise diagnosis backed up by research and to correct any metabolic factors (diabetes, hyperuricemia, hypercholesterolemia, dysthyroidism) ${ }^{27}$. PRP effectiveness may be compromised by medications including quinolones, corticoides (orally or by infiltration), or statins ${ }^{27,28}$. These families of drugs accelerate tendon degeneration, which may lead to rupture 28,29 . Finally, sports technical mistakes and technopathies should also be corrected as well as a control of the physical stresses (sports or work).

\section{Indications for PRP infiltration}

Patients likely to benefit from PRP infiltration must be selected: relevant indications (but still debated in literature) relate to chronic corporeal tendinopathies (patellar, Achilles) which are resistant to conservative therapies (including prolonged eccentric rehabilitation and shock waves), without any osseous impingement or luxation ${ }^{30}$. It is imperative to surgically correct any osseous impingements (Haglund deformity, subacromial impingement and a Bigliani type III acromion, Sinding-Larsen-Johansson sequelae, etc.) before envisaging any further PRP infiltration ${ }^{30}$. Enthesopathies (epicondylitis, jumper's knee, Achilles)may, in theory, benefit from PRP infiltration, although results remain less favourable, as with other treatments (such as shock waves), because of their particular histological structure ${ }^{30}$. For all inflammatory pathologies (e.g. enthesopathy in the context of a spondylarthropathy), it is crucial to treat the underlying inflammatory disease.

\section{Therapeutic protocol}

Although the product diffuses from the site of the injection $^{31}$, it is best to conduct the infiltration in the tendon lesion using ultrasound, while respecting aseptic precautions ${ }^{32}$. A local anaesthetic is not recommended as it compromises the therapeutic potential of PRP: the anaesthetic may effectively reduce local $\mathrm{pH}$, which is responsible for the inhibition and reduction or absence of platelet degranulation ${ }^{21,22,33}$. It was thus more recommended to use a small needle (30G) to decrease pain ${ }^{33}$. Although PRP is naturally activated upon contact with denatured collagen, platelet pre-activation (e.g. by $\mathrm{CaCl}_{2}$ ) promotes degranulation and thus the release of the growth factors involved in tissue healing ${ }^{13}$. A pH lower than than 7.7 inhibits platelet activation while a $\mathrm{pH}$ greater than 8.0 stimulates it. As the citrate used for the anticoagulation is slightly acidic, it is thus recommended to add a basic buffer like $\mathrm{NaHCO}_{3}$ before injection ${ }^{21}$.

After activation, $70 \%$ of the platelet growth factors are released from the $\alpha$-granules within the first $10 \mathrm{~min}$ utes, and almost $100 \%$ have been secreted within the first hour ${ }^{34}$.

Even though there is no general agreement on the volume to be injected, 3 to $6 \mathrm{~mL}$ of PRP could be injected in the tendon, depending on its caliber. It could be interesting to determine whether the injected volume of PRP could influence the healing process based on the "degenerative state» of the tendon. Likewise, whether we should modify the protocol in case of enthesopathy or middle substance tendinopathy has never been investigated.

Post-infiltration consequences are often painful and may justify the use of local cryotherapy and analgesics. NSAIDs are to be avoided for 21 days following the procedure, as they may inhibit the PRP effect $^{22,35}$. Once the algesic period has passed, progressively intensive sub-maximum eccentric rehabilitation, combined with stretching, will 'guide' tendon healing ${ }^{36}$. In animals, active mobilization of the infiltrated tendon improves tendon healing ${ }^{37}$; eccentric rehabilitation is more effective than concentric work ${ }^{38}$. For the first four to six weeks post-infiltration, rest from sport is necessary to avoid any new intra-tendinous lesions occurring; only rehabilitation, below the 
pain threshold, is permitted ${ }^{16}$. When sport is gradually resumed (reathletisation), any possible techniquerelated problems should be corrected and the tendon should be somewhat 'protected' using 'functional' orthoses (e.g. patellar brace) or 'strapping'39.

In our series on the use of PRP to treat jumper's knee, we have observed that younger patients respond more effectively to treatment, most probably because of their greater healing potential ${ }^{16,40}$. Those suffering from jumper's knee for less than 10.5 months make the greatest progress ${ }^{40}$. Patients initially presenting with better quadricipital isocentric results during eccentric contraction at $30 \%$ and concentric contraction at $60 \%$ make better progress ${ }^{16}$. Moreover, patients presenting a significant reduction in pain after three months continue to progress positively up to one year later ${ }^{40}$. The three-month assessment looks at the effect of PRP infiltration and allows for a discussion to take place on the indication for a second PRP infiltration in the event of partial improvement to the tendinous symptoms ${ }^{41}$. Indeed, it was demonstrated that it was not useful to carry out 2 closely-timed infiltrations $^{42}$. Surgery should be discussed in the absence of any improvement 40 .

In case of several applications, the refrigeration or lyophylisation of platelet could be performed ${ }^{43,44}$. However, after PRP freezing-thawing, platelets are lyzed and a platelet lysate is obtained ${ }^{44}$. It has been demonstrated that platelet lysate increase the growth rate of mesenchymal stem cells ${ }^{45}$.

\section{Conclusion}

$\mathrm{PRP}$ is a recent but controversial treatment for chronic tendinopathies. Standardization will be important to compare results and advance progress in the field, but it seems likely that more knowledge is awaited before proper standardization can be achieved. The first stage includes selecting the correct therapeutic indications and correcting the risk factors for tendinopathies. Subsequently, improving the techniques for obtaining PRP is crucial, as the injection protocol. Finally, post-infiltration rehabilitation remains absolutely necessary.

\section{References}

1. Smets F, Croisier JL, Forthomme B, Crielaard JM, Kaux JF Applications cliniques du Plasma riche en plaquettes (PRP) dans les lésions tendineuses: revue de la littérature. Science \& Sport. 2012;27:141-153.

2. Kaux JF, Drion PV, Colige A, Pascon F, Libertiaux V, Hoffmann $A$, et al. Effects of platelet-rich plasma (PRP) on the healing of Achilles tendons of rats. Wound Repair Regen. 2012;20:748-756.

3. Kaux JF, Crielaard JM. Platelet-rich plasma application in the management of chronic tendinopathies. Acta Orthop Belg. 2013;79(1):10-15.

4. Andia I, Latorre PM, Gomez MC, Burgos-Alonso N, Abate M, Maffulli N. Platelet-rich plasma in the conservative treatment of painful tendinopathy: a systematic review and meta-analysis of controlled studies. Br Med Bull. 2014;110(1):99-115.

5. de Vos RJ, Windt J, Weir A. Strong evidence against plateletrich plasma injections for chronic lateral epicondylar tendinopathy: a systematic review. Br J Sports Med. 2014;48(12):952956.

6. Padulo J, Oliva F, Frizziero A, Maffulli N. Muscles, Ligaments and Tendons Journal. Basic principles and recommendations in clinical and field science. MLTJ. 2013;4:250-252.

7. Dohan Ehrenfest DM, Rasmusson L, Albrektsson T. Classification of platelet concentrates: from pure platelet-rich plasma (P-PRP) to leucocyte- and platelet-rich fibrin (L-PRF). Trends Biotechnol. 2009;27(3):158-167.

8. Kaux JF, Le Goff C, Seidel L, Peters P, Gothot A, Albert A, et al. Comparative study of five techniques of preparation of platelet-rich plasma. Pathol Biol (Paris). 2011;59(3):157-160.

9. Kaux JF, Le Goff C, Renouf J, Peters P, Lutteri L, Gothot A, et al. Comparison of the platelet concentrations obtained in platelet-rich plasma (PRP) between the GPS II and GPS III systems. Pathol Biol (Paris). 2011;59(5):275-277.

10. Malgoyre A, Bigard X, Alonso A, Sanchez MFK. Variabilité des compositions cellulaire et moléculaire des extraits de concentrés plaquettaires (platelet-rich plasma, PRP). Journal de Traumatologie du Sport. 2012;29:236-240.

11. Weibrich G, Kleis WK, Hitzler WE, Hafner G. Comparison of the platelet concentrate collection system with the plasmarich-in-growth-factors kit to produce platelet-rich plasma: a technical report. Int J Oral Maxillofac Implants. 2005;20(1) 118-123.

12. Anitua E. What is PRGF? In: Anitua E, editor. A biological approach to implantology. Vittoria. 2009;55-66.

13. Lopez-Vidriero E, Goulding KA, Simon DA, Sanchez M, Johnson $\mathrm{DH}$. The use of platelet-rich plasma in arthroscopy and sports medicine: optimizing the healing environment. Arthroscopy. 2010;26(2):269-278.

14. McCarrel TM, Minas T, Fortier LA. Optimization of leukocyte concentration in platelet-rich plasma for the treatment of tendinopathy. J Bone Joint Surg Am. 2012;94(19):e143(1-8).

15. Moog R, Zeiler T, Heuft HG, Stephan B, Fischer EG, Kretschmer $\mathrm{V}$, et al. Collection of WBC-reduced single-donor PLT concentrates with a new blood cell separator: results of a multicenter study. Transfusion. 2003;43(8):1107-1114.

16. Kaux JF, Croisier JL, Bruyere O, et al. One injection of plateletrich plasma associated to a submaximal eccentric protocol to treat chronic jumper's knee. J Sports Med Phys Fitness. 2014.

17. Anitua E, Sanchez M, Prado R, Orive G. The type of plateletrich plasma may influence the safety of the approach. Knee Surg Sports Traumatol Arthrosc. 2012;22(7):1708-1709.

18. Intravia J, Allen DA, Durant TJ, McCarthy MB, Russell R, Beitzel $\mathrm{K}$, et al. In vitro evaluation of the anti-bacterial effect of two preparations of platelet rich plasma compared with cefazolin and whole blood. Muscles, Ligaments and Tendons Journal. 2014;4(1):79-84.

19. Ahuja KD, Thomas GA, Adams MJ, Ball MJ. Postprandial platelet aggregation: effects of different meals and glycemic index. Eur J Clin Nutr. 2012;66(6):722-726.

20. Geerts SO, Nys M, De MP, Charpentier J, Albert A, Legrand V, et al. Systemic release of endotoxins induced by gentle mastication: association with periodontitis severity. J Periodontol. 2002;73(1):73-78.

21. Laffan M, Manning R. Investigation of haemostasis. In: Lewis SM, Brain BJ, Bates I, editors. Practical haematology. 10th ed. London: Churchill Livingstone. 2006;380-440.

22. Foster TE, Puskas BL, Mandelbaum BR, Gerhardt MB, Rodeo SA. Platelet-rich plasma: from basic science to clinical applications. Am J Sports Med. 2009;37(11):2259-2272.

23. Harrison P, Mackie I, Mumford A, Briggs C, Liesner R, Winter M, et al. Guidelines for the laboratory investigation of heritable disorders of platelet function. Br J Haematol. 2011;155(1):30-44. 
24. Cattaneo M, Cerletti C, Harrison P, Hayward CP, Kenny D, Nugent $\mathrm{D}$, et al. Recommendations for the Standardization of Light Transmission Aggregometry: A Consensus of the Working Party from the Platelet Physiology Subcommittee of SSC/ISTH. J Thromb Haemost. 2013.

25. Born GV, Cross MJ. The Aggregation of Blood Platelets. J Physiol. 1963;168:178-195.

26. Greinacher A. Platelet activation by heparin. Blood. 2011; 117(18):4686-4687.

27. Kaux JF, Forthomme B, Le Goff C, Crielaard JM, Croisier JL. Current opinion on tendinopathy. Journal of Sports Science and Medicine. 2011;10:238-253.

28. Kirchgesner T, Larbi A, Omoumi P, Malghem J, Zamali N, Manelfe J, et al. Drug-induced tendinopathy: From physiology to clinical applications. Joint Bone Spine. 2014.

29. Chen SK, Lu CC, Chou PH, Guo LY, Wu WL. Patellar tendon ruptures in weight lifters after local steroid injections. Arch Orthop Trauma Surg. 2009;129(3):369-372.

30. Fichez O. Bonnes et mauvaises indications de l'injection de PRP dans les tendinopathies chroniques du sportif. In: Bard H, Bianchi S, Brasseur JL, Djian P, Guerini H, Lapègue F, et al., editors. Le tendon et son environnement: Sauramps Médical. 2013;243-252.

31. Loftus ML, Endo Y, Adler RS. Retrospective analysis of postinjection ultrasound imaging after platelet-rich plasma or autologous blood: observational review of anatomic distribution of injected material. AJR Am J Roentgenol. 2012;199(4):W501-505.

32. Engebretsen L, Steffen K, Alsousou J, Anitua E, BachI N, Devilee $\mathrm{R}$, et al. IOC consensus paper on the use of platelet-rich plasma in sports medicine. Br J Sports Med. 2010;44(15): 1072-1081.

33. Bausset O, Magalon J, Giraudo L, Louis ML, Serratrice N, Frere $C$, et al. Impact of local anaesthetics and needle calibres used for painless PRP injections on platelet functionality. Muscles, ligaments and tendons journal. 2014;4(1):18-23.

34. Marx RE. Platelet-rich plasma (PRP): what is PRP and what is not PRP? Implant Dent. 2001;10(4):225-228.

35. Nguyen RT, Borg-Stein J, Mclnnis K. Applications of plateletrich plasma in musculoskeletal and sports medicine: an evi- dence-based approach. PM R. 2011;3(3):226-250.

36. Kaux JF, Forthomme B, Namurois MH, Bauvir P, Defawe N, Delvaux $F$, et al. Description of a standardized rehabilitation program based on sub-maximal eccentric following a plateletrich plasma infiltration for jumper's knee. Muscles, Ligaments and Tendons Journal. 2014;4(1):85-89.

37. Virchenko O, Aspenberg P. How can one platelet injection after tendon injury lead to a stronger tendon after 4 weeks? Interplay between early regeneration and mechanical stimulation. Acta Orthop. 2006;77(5):806-812.

38. Kaux JF, Drion P, Libertiaux V, Colige A, Hoffmann A, Nusgens $B$, et al. Eccentric training improves tendon biomechanical properties: a rat model. J Orthop Res. 2013;31(1):119-124.

39. Clifford AM, Harrington $E$. The effect of patellar taping on squat depth and the perception of pain in people with anterior knee pain. Journal of human kinetics. 2013;37:109-117.

40. Kaux JF, Bruyere O, Croisier JL, et al. One-year follow-up of platelet-rich plasma infiltration to treat chronic upper patellar tendinopathies. Acta Orthop Belg. In Press.

41. Dallaudiere B, Meyer P, Hummel V, Perozziello A, Peuchant A, Moreau-Durieux $\mathrm{MH}$, et al. Efficacy of second intra-tendinous platelet-rich-plasma injection in case of incomplete response of the first injection: three-year follow up experience. Diagnostic and interventional imaging. 2013;94(9):871-877.

42. Kaux JF, Croisier JL, Forthomme B, et al. Using platelet-rich plasma to treat jumper's knees: exploring the effects of a second closely-timed infiltration. J Sci Med Sport. In Press.

43. Cap AP, Perkins JG. Lyophilized platelets: challenges and opportunities. J Trauma. 2011;70 (5 Suppl):S59-60.

44. Jonsdottir-Buch SM, Lieder R, Sigurjonsson OE. Platelet lysates produced from expired platelet concentrates support growth and osteogenic differentiation of mesenchymal stem cells. PLoS One. 2013;8(7):e68984.

45. Ben Azouna N, Jenhani F, Regaeya Z, Berraeis L, Ben Othman T, Ducrocq E, et al. Phenotypical and functional characteristics of mesenchymal stem cells from bone marrow: comparison of culture using different media supplemented with human platelet lysate or fetal bovine serum. Stem cell research \& therapy. 2012; 3(1):6. 